\title{
HYPOTHALAMIC REGULATION OF FEMALE SEXUAL BEHAVIOUR; ESTABLISHMENT OF BEHAVIOURAL OESTRUS IN SPAYED GUINEA-PIGS FOLLOWING HYPOTHALAMIC LESIONS
}

\author{
ROBERT W. GOY* AND GHARLES H. PHOENIX \\ Department of Psychiatry, University of Kansas, Lawrence, Kansas, U.S.A.
}

(Received 26th Fune 1962)

\begin{abstract}
Summary. Individual characteristics of sexual behaviour were empirically determined for twenty-seven spayed female guinea-pigs given three standardized tests after injection with $0.0034 \mathrm{mg}$ of oestradiol benzoate and, $36 \mathrm{hr}$ later, $0.4 \mathrm{mg}$ of progesterone. Following this preoperative series of tests, hypothalamic lesions were produced electrolytically at different loci with various parameters of current duration and intensity. Alterations in the patterns of sexual behaviour displayed on three postoperative tests with identical hormonal treatments were evaluated statistically for each individual.

Posteroventral hypothalamic lesions involving mammillary and premammillary structures were not associated with significant behavioural changes ( $\mathcal{N}$ equals 4$)$. Mid-ventral lesions were associated with alterations in response patterns in all but two animals. The behavioural changes were not correlated with size of lesions. Nine females with complete behavioural losses failed to display any signs of receptivity postoperatively. Ten showed statistically significant but incomplete losses in one or more of the components comprising the pattern of sexual behaviour, and two females displayed behavioural oestrus postoperatively in the absence of exogenous hormone. Lesions in females with behavioural oestrus appear to be more anterior and possibly more medial than those which eliminate sexual behaviour. Uteri of behavioural-oestrous females were atrophic suggesting that no oestrogen was provided by endogenous sources.

The results suggest that mechanisms for both the facilitation and inhibition of female sexual behaviour exist within the hypothalamus. Moreover, hypothalamic regulation of reproductive behaviour is quantitative in nature, not 'all-or-none', and a range of partial deficits in behaviour can be observed after hypothalamic damage.
\end{abstract}

* Present address: Wisconsin Regional Primate Center, 22 N. Gharter Street, Madison, Wisconsin, U.S.A. 


\section{INTRODUCTION}

Investigators interested in the role of the hypothalamus in the expression of emotional and motivated behaviours have demonstrated systems of neurons which augment or depress behavioural expression or act antagonistically in other ways. For the motivated behaviour of eating, regions governing both its activation ('feeding or appetite centres', Anand \& Brobeck, 1951) and termination ('satiety centres', Hetherington \& Ranson, 1940) have been studied. For emotional activities, areas involved in the mediation of both attack behaviour and its opposite of flight or withdrawal have been reported (Wheatley, 1944; Nakao, 1958). A number of authors believe that the neural regulation of these behaviours depends on a selective facilitation or inhibition of final effector systems and generally agree that the neural mechanisms subserving these functions lie within the diencephalon (Patton, 1961; Ruch, 1961; Brobeck, 1960; Stellar, 1960).

The hypothesis of diencephalic mechanisms for facilitation and inhibition has received less general acceptance for sexual behaviour than for eating behaviour. Evidence for a hypothalamic sexual facilitating mechanism has been obtained consistently in a variety of mammalian species such as the guineapig (Brookhart, Dey \& Ranson, 1940; Brookhart \& Dey, 1941; Dey, 1943 a, b) Goy \& Phoenix, 1960; Phoenix, 1961), rat (Law \& Meagher, 1958; Clark, 1942; Soulairac, 1959; Soulairac, Soulairac \& Giabicani-Teysseyre, 1958), cat and rabbit (Sawyer \& Robinson, 1956) and ewe (Clegg, Santolucito, Smith \& Ganong, 1958). Not since the work of Law \& Meagher (1958), however, has evidence been presented for a hypothalamic inhibitory mechanism involved in the regulation and display of sexual behaviour. In their experiments, after certain lesions in the mid-ventral hypothalamus, female rats with intact ovaries displayed receptive behaviour in the absence of vaginal oestrus. Moreover, spayed female rats displayed receptive behaviour without administration of exogenous hormones. If the existence of such an inhibitory centre could be demonstrated in another species it would (1) provide the basis for a more general acceptance of such a mechanism, and (2) suggest much for concepts of neuro-endocrine interactions in the determination of reproductive behaviour (Sawyer, 1959, 1960). The present experiments provide evidence for the existence of an inhibitory centre in the female guinea-pig. In addition the data permit a more accurate determination of the locus of the facilitating mechanism than has been reported for this species.

\section{MATERIALS AND METHODS}

\section{ANIMALS}

Twenty-seven female guinea-pigs, 6 to 9 months old at the beginning of the study, were used. All animals were spayed at least 2 weeks prior to testing. They were housed in large cages in groups containing six to nine animals. Food and water were available at all times. The regular diet of standard laboratory rabbit chow mixed with oats was supplemented daily with alfalfa and fresh cabbage. 
PROCEDURE

Thirty-six hours prior to testing, the animals were placed in individual cages and given a subcutaneous injection of $0.0034 \mathrm{mg}$ of oestradiol benzoate. Thirtysix hours later, i.e. on the day of testing, they were injected with $0.4 \mathrm{mg}$ of progesterone. After injection with progesterone, twelve attempts at hourly intervals were made to elicit the lordosis reflex. The first hour in which the reflex was elicited was recorded as the onset of heat, and latency to heat was computed as the number of hours from the time of progesterone injection to the first lordosis response. The duration of each lordosis response was recorded, and the response of longest duration, the maximum lordosis, was taken as a measure of response strength. Descriptive details of the behavioural measures have been reported previously (Goy \& Young, 1957).

Data on mounting activity were obtained by observing each female for 10 min while paired with an oestrous stimulus female. Such individual tests were given 7 to $9 \mathrm{hr}$ after the injection of progesterone regardless of the occurrence of oestrus.

All animals were given three pre- and three postoperative tests. The interval between tests varied from 2 to 4 weeks. To determine a base line of mounting frequency in the absence of the ovarian hormones, ten females were each given two additional tests preoperatively without hormone injection. Six of the ten displayed mounting on these tests and data from them were used for comparison with residual mounting activity displayed by postoperative females injected with hormones.

Following the preoperative series of tests, electrolytic lesions at various hypothalamic loci were produced in all animals with the aid of a stereotaxic instrument. The operative procedure was similar to that previously reported for lesions in the male guinea-pig (Phoenix, 1961). Left-right and anteriorposterior distances were measured from bregma. Vertical distances were measured from the cranial floor. An effort was made to produce lesions at different loci by systematically varying the stereotaxic coordinates primarily in the anterior-posterior axis. Variations in lesion size were also attempted. Either two or three electrolytic lesions were produced by passing a direct current of 2 or 3 milliamps through a unipolar anode of stainless steel. The current was applied for 20 or 30 sec.

One or 2 weeks after operation the postoperative series of tests was started. Following the last regular postoperative tests, eleven animals were given daily injections of $2.5 \mathrm{mg}$ of testosterone propionate for 14 days. On the final day of injection, they were tested for mounting behaviour by placing a receptive stimulus female with them for $10 \mathrm{~min}$.

In the summary of data, the means of each individual were based on tests when oestrus occurred, with the exception of mounting which was based on all tests. Thus, if a female came into heat on two of three tests, the mean latency and mean maximum lordosis were based on the two tests on which she was in heat, but the mean for mounting was based on all three tests.

Changes in performance after the hypothalamic operations were evaluated statistically for each individual by the chi-square technique with Fisher's exact test. The data for each measure obtained from the pre- and postoperative tests 
were classified according to whether they fell above or below the common median. Significance at $P<0.05$ required that the pre- and postoperative distributions displayed no overlap.

\section{ANATOMY}

The animals were killed following the last postoperative test by perfusion through the heart with physiological saline solution followed by $10 \%$ formalin or Bouin's fixative. The brains were allowed to remain in fixative from 1 to 8 weeks. They were then dehydrated in alcohols, embedded in paraffin, and sectioned transversely at $15 \mu$. Every fifth section was mounted and stained with Luxol Fast Blue MBSN (Dupont) and Bayer's cresyl violet following the method described by Klüver \& Barrera (1953).

Microscopic examination of each brain was carried out independently by each author. Good inter-observer agreement was obtained, and, where discrepancies in ratings occurred, the areas were re-examined and a common evaluation was achieved. Each of eighteen areas or nuclear regions within the hypothalamus was rated for damage on a three-point scale. A rating of zero was ascribed to nuclei with damage estimated to be between 0 and $10 \%$; with 10 to $90 \%$ damage, the nucleus was rated 1 , and $90 \%$ damage or over was rated 2. With the exceptions of the anterior and posterior median eminence and the supra-optic commissures, corresponding nuclei in the left and right halves of the brain were rated separately.

The nomenclature adopted was drawn largely from Kreig (1932) and Gurdjian (1927) with the following slight modifications. We have followed Gurdjian in distinguishing a nucleus supraopticus diffusus which Kreig includes in the anterior hypothalamic area. Because of its relatively large size the periventricular nucleus was divided for accuracy in rating into an anterior and posterior part. The dividing region (in transverse section) was on a plane approximately midway through the long axis of the ventromedial nucleus. Similarly, we divided what Kreig has called the arcuate nucleus into an anterior and posterior part with the infundibular recess serving as the region of transition. Our premammillary area includes both the nucleus ventralis and premammillaris dorsalis of Kreig. No distinction was made between the ventromedial nucleus pars anterioris, medialis, lateralis and centralis, all being included in the ventromedial nucleus; but we have retained Kreig's distinction of the posterior portion of the ventromedial nucleus. The division of the median eminence into an anterior and posterior part follows the description adopted by Rioch, Wislocki \& O'Leary (1940).

\section{RESULTS}

\section{BEHAVIOURAL RESULTS}

A summary of the pre- and postoperative performance of each individual is presented in Table 1. For six of the females studied, the differences between pre- and postoperative performance were not statistically significant, and the animals were classified as 'no deficit' or 'controls'.

Statistically significant changes in performance noted after the hypothalamic operations were of three relatively distinct types. Two of these types were 
characterized by deficiencies in sexual performance but differed in the degree or extent of the deficits. The type which we have called 'severe deficit' (Table 1) was characterized by a complete disappearance of the lordosis postoperatively and, most often, by a corresponding elimination of all mounting activity. Nine females showed this type of severe deficit in postoperative performance. A less

\section{TABLE 1}

SUMMARY OF THE PRE- AND POSTOPERATIVE SEXUAL PERFORMANCES OF SPAYED GUINEA-PIGS TREATED WITH OESTRADIOL AND PROGESTERONE

\begin{tabular}{|c|c|c|c|c|c|c|c|c|c|}
\hline & & \multicolumn{2}{|c|}{$\begin{array}{c}\text { Tests } \\
\text { positive for heat } \\
(\%)\end{array}$} & \multicolumn{2}{|c|}{$\begin{array}{l}\text { Latency to } \\
\text { heat } \\
(h r)\end{array}$} & \multicolumn{2}{|c|}{$\begin{array}{l}\text { Mean duration of } \\
\text { maximum lordosis } \\
\qquad(\mathrm{sec})\end{array}$} & \multicolumn{2}{|c|}{$\underset{\text { mounts }}{\text { Mean No. }}$} \\
\hline & & Pre & Post & Pre & Post & Pre & Post & Pre & Post \\
\hline $\begin{array}{l}\text { Severe } \\
\text { deficit }\end{array}$ & $\begin{array}{l}3514 * * \\
3520 * * \\
3574 * * \\
3988 * * \\
4078 \\
4124 * * \\
4189 * * \\
4190 \\
4202\end{array}$ & $\begin{array}{l}100 \\
100 \\
100 \\
100 \\
100 \\
100 \\
100 \\
100 \\
100\end{array}$ & $\begin{array}{l}0 \\
0 \\
0 \\
0 \\
0 \\
0 \\
0 \\
0 \\
0\end{array}$ & $\begin{array}{l}5 \cdot 7 \\
6 \cdot 7 \\
6 \cdot 7 \\
4 \cdot 0 \\
4 \cdot 3 \\
3 \cdot 0 \\
6 \cdot 0 \\
5 \cdot 7 \\
3 \cdot 0\end{array}$ & $\begin{array}{l}13 \\
13 \\
13 \\
13 \\
13^{*} \\
13 \\
13 \\
13^{*} \\
13\end{array}$ & $\begin{array}{r}9 \cdot 7 \\
17 \cdot 3 \\
33 \cdot 3 \\
11 \cdot 0 \\
6 \cdot 0 \\
12 \cdot 3 \\
9 \cdot 0 \\
11 \cdot 0 \\
10 \cdot 0\end{array}$ & $\begin{array}{l}0 \\
0 \\
0 \\
0 \\
0 * \\
0 \\
0 \\
0^{*} \\
0\end{array}$ & $\begin{array}{r}9 \cdot 3 \\
14 \cdot 0 \\
33 \cdot 7 \\
45 \cdot 0 \\
17 \cdot 3 \\
12 \cdot 7 \\
14 \cdot 3 \\
8 \cdot 0 \\
68 \cdot 0\end{array}$ & $\begin{array}{l}0 \\
0 \\
0 \\
0 \\
2 \cdot 0 \\
0 \cdot 3 \\
0 \\
0 \\
2 \cdot 7\end{array}$ \\
\hline $\begin{array}{l}\text { Partial } \\
\text { deficit }\end{array}$ & $\begin{array}{l}3540 \\
3856 \\
3918 \\
3920 \\
3985 \\
3987 \\
3990 \\
4123 \\
3557 \\
3558\end{array}$ & $\begin{array}{l}100 \\
100 \\
100 \\
100 \\
100 \\
100 \\
100 \\
100 \\
100 \\
100\end{array}$ & $\begin{array}{r}67 \\
100 \\
67 \\
67 \\
100 \\
100 \\
67 \\
100 \\
100 \\
100\end{array}$ & $\begin{array}{l}4 \cdot 0 \\
4 \cdot 0 \\
4 \cdot 7 \\
4 \cdot 0 \\
2 \cdot 0 \\
3 \cdot 3 \\
2 \cdot 7 \\
3 \cdot 3 \\
5 \cdot 3 \\
7 \cdot 3\end{array}$ & $\begin{array}{l}8 \cdot 0^{*} \\
7 \cdot 0^{*} \\
9 \cdot 5^{*} \\
8 \cdot 0^{*} \\
4 \cdot 3 \\
3 \cdot 3 \\
5 \cdot 0^{*} \\
6 \cdot 7^{*} \\
8 \cdot 0 \\
7 \cdot 0\end{array}$ & $\begin{array}{r}35 \cdot 7 \\
8 \cdot 3 \\
8 \cdot 3 \\
15 \cdot 0 \\
18 \cdot 3 \\
19 \cdot 0 \\
10 \cdot 7 \\
10 \cdot 0 \\
23 \cdot 0 \\
23 \cdot 0\end{array}$ & $\begin{array}{c}12 \cdot 0^{*} \\
7 \cdot 0 \\
4 \cdot 5^{*} \\
6 \cdot 0^{*} \\
8 \cdot 7^{*} \\
7 \cdot 3^{*} \\
13 \cdot 0 \\
6 \cdot 3 \\
12 \cdot 0 \\
15 \cdot 3\end{array}$ & $\begin{array}{c}3 \cdot 3 \\
13 \cdot 7 \\
13 \cdot 0 \\
4 \cdot 7 \\
9 \cdot 3 \\
0 \\
20 \cdot 7 \\
3 \cdot 0 \\
13 \cdot 3 \\
24 \cdot 7\end{array}$ & $\begin{array}{l}0 \\
3 \cdot 7^{*} \\
0 * \\
0 \cdot 7^{*} \\
0 \\
0 \\
6 \cdot 0 \\
9 \cdot 3 \\
1 \cdot 7 * \\
10 \cdot 3 *\end{array}$ \\
\hline $\begin{array}{l}\text { No deficit } \\
\text { (controls) }\end{array}$ & $\begin{array}{l}3555 \\
3989 \\
4033 \\
3919 \\
4035 \\
4259\end{array}$ & $\begin{array}{r}67 \\
100 \\
100 \\
100 \\
100 \\
100\end{array}$ & $\begin{array}{l}100 \\
100 \\
100 \\
100 \\
100 \\
100\end{array}$ & $\begin{array}{l}8 \cdot 5 \\
4 \cdot 3 \\
4 \cdot 0 \\
5 \cdot 0 \\
4 \cdot 7 \\
4 \cdot 3\end{array}$ & $\begin{array}{l}6 \cdot 7 \\
3 \cdot 7 \\
4 \cdot 0 \\
4 \cdot 0 \\
2 \cdot 0 \\
5 \cdot 0\end{array}$ & $\begin{array}{r}10.0 \\
5.7 \\
8.0 \\
12.7 \\
11.7 \\
7.3\end{array}$ & $\begin{array}{r}12 \cdot 7 \\
6 \cdot 7 \\
8 \cdot 0 \\
8 \cdot 7 \\
8 \cdot 0 \\
6 \cdot 0\end{array}$ & $\begin{array}{r}7 \cdot 3 \\
0 \\
3 \cdot 0 \\
0 \cdot 7 \\
14 \cdot 3 \\
1 \cdot 0\end{array}$ & $\begin{array}{l}7 \cdot 3 \\
0 \\
5 \cdot 7 \\
0 \\
6 \cdot 0 \\
6 \cdot 3\end{array}$ \\
\hline $\begin{array}{l}\text { Behavioural } \\
\text { oestrus }\end{array}$ & $\begin{array}{l}4077 \\
4191\end{array}$ & $\begin{array}{l}100 \\
100\end{array}$ & $\begin{array}{l}100 \\
100\end{array}$ & $\begin{array}{l}4 \cdot 3 \\
5 \cdot 3\end{array}$ & $\begin{array}{l}0^{*} \\
0^{*}\end{array}$ & $\begin{array}{r}8 \cdot 3 \\
10 \cdot 3\end{array}$ & $\begin{array}{r}7 \cdot 7 \\
10 \cdot 7\end{array}$ & $\begin{array}{l}8 \cdot 0 \\
0 \cdot 3\end{array}$ & $\begin{array}{l}0^{*} \\
0\end{array}$ \\
\hline
\end{tabular}

* Change from pre- to postoperative performance significant at $P<0 \cdot 05$.

** Change from pre- to postoperative performance significant at $P<0.05$ for all measures.

extreme type of loss which we have called 'partial deficit' was found for ten females. In this condition, intermediate decrements in the individual means for maximum lordosis and/or mounting activity occurred. A significant increase in latency to oestrus might be the only change in performance detected, but in general, animals classified in the 'partial deficit' group showed deficiencies in at least two of the four measures of sexual performance studied (i.e. percentage of tests positive for oestrus, latency, maximum lordosis, and number of mounts).

Not only was the maximum duration of lordosis shorter for the partial deficit group, but weaker lordosis responses were obtained on every hourly test post- 
operatively than had been obtained prior to operation (Text-fig. 1). Tests negative for oestrus are not included in the curves presented in Text-fig. 1. Thus the depression of the postoperative values for lordosis cannot be attributed

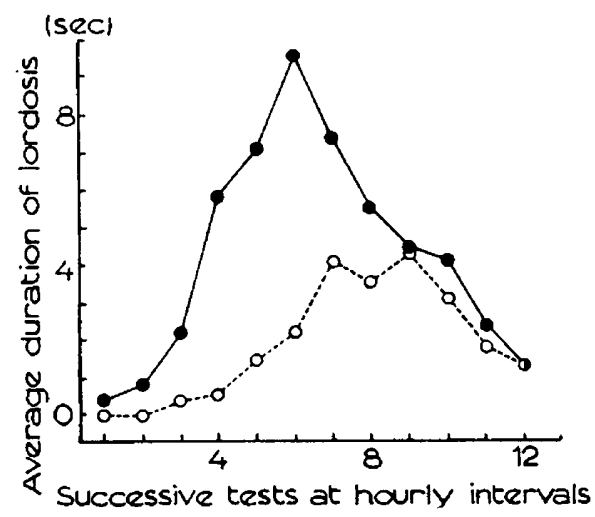

Text-FIG. 1. Partial deficit in the capacity to display lordosis after hypothalamic lesions. The duration of the response is consistently shorter on postoperative tests, but it is not completely eliminated in any female represented here.

$$
\left.\begin{array}{l}
\text { Preoperative } \\
0 \ldots \text { Postoperative }
\end{array}\right\} \mathcal{N}=10
$$

simply to a lower incidence of oestrus, but accurately reflects the less intense character of lordosis when displayed.

The third type of postoperative change, called 'behavioural oestrus', was found in two individuals. One of the essential characteristics of this condition (a significant reduction in latency to oestrus) is recorded in Table 1. In addition,

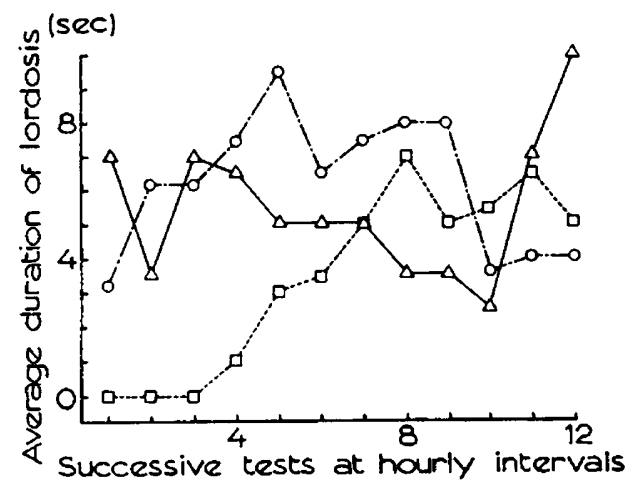

Texr-FIG. 2. Establishment of behavioural oestrus by hypothalamic lesions in spayed females (Nos. 4077 and 4191) without hormonal treatment. Note that in the two upper postoperative curves of performance there is no latent period to the onset of the lordosis response, and all responses show substantial duration postoperatively.

$$
\Delta \text { _. } \triangle \text { Postoperative (no hormone) }
$$

the condition is characterized by (a) the display of lordosis on tests when no exogenous hormone is given and (b) the display of lordosis at or near maximum duration on all tests. As shown in Text-fig. 2, a gradual increase in the duration 
of lordosis to a maximum value on the eighth hourly test after progesterone was characteristic of the preoperative display of lordosis by these females. In contrast, the display of lordosis at or near maximum values on all hourly tests was characteristic of their postoperative performances regardless of whether oestradiol and progesterone were given.

Evidence indicates that the behavioural oestrus appeared immediately after operation, persisted as a continuous state of readiness to respond to appropriate stimulation, and was not peculiar to the type of stimulation used to elicit it in our standardized tests. One of these females (4077) was tested and displayed the lordosis as soon as postoperative recovery from anaesthetic permitted. Although we did not test continuously for the lordosis response, we never failed to obtain it on those occasions when tests were made. Both females were tested at irregular times during the intervals between formal 12-hr tests and consistently responded with lordosis. The sexual response was also displayed by Female 4077 without hormone administration in response to the mounting activity of a normal male guinea-pig. At the time the test was made the vaginal membrane was intact. Complete acceptance of the male (defined as permitting intromission) was therefore impossible.

The behavioural oestrus observed in these two females was not due to oestrogenic substances derived from endogenous sources. Both females were examined daily for 3 weeks during which time their vaginal membranes never ruptured. At the time of sacrifice, although lordosis responses were still being displayed regularly, no ovarian fragments or nodules were found. The uteri appeared completely atrophic. Histological sections of the uteri (Pl. 1, Figs. 6 and 7) showed no oestrogenic stimulation and sections of the adrenals were normal.

The postoperative changes in mounting behaviour did not correlate with the postoperative changes in other measures. Of nine females in which lordosis was completely eliminated after operation, three continued to display mounting although the frequency was greatly reduced. Conversely, four females (3856, 3557,3558 and 4077, a 'behavioural oestrus' female) showed significant reductions in mounting behaviour, but the maximum lordosis was either unaltered or only slightly reduced in duration.

Mounting behaviour was relatively refractory or no longer susceptible to hormonal influence postoperatively. The median number of mounts was 2.4 per animal per test for the eight females that continued to display mounting at a reduced frequency postoperatively. This value did not differ significantly from that obtained from six unoperated spayed females that mounted on tests without oestradiol benzoate and progesterone (median $=2.2$ mounts per animal per test, $\mathrm{U}=25, P>0 \cdot 10)$. Thus animals that continued to mount postoperatively but at significantly reduced frequencies displayed only that amount which could be obtained from ovariectomized females without hormonal treatment.

Attempts to activate mounting behaviour by treatment with testosterone propionate did not yield clear-cut results (Table 2). When four females that displayed some mounting postoperatively (Group A in Table 2) were injected daily with $2.5 \mathrm{mg}$ testosterone propionate for 2 weeks, two females increased 
and two decreased in frequency of mounting and the median number of mounts did not significantly change. Seven females that showed no mounting postoperatively (Group B in Table 2) were similarly treated with testosterone propionate. Of these, six showed increases in mounting and one remained the same. However, testosterone propionate did not have the ability to restore the median number of mounts to the value obtained in preoperative tests with oestradiol benzoate and progesterone for either Group A or B.

TABLE 2

EFFECT OF OESTRADIOL AND PROGESTERONE OR TESTOSTERONE PROPIONATE ON MOUNTING BEHAVIOUR IN SPAYED FEMALE GUINEAPIGS WITH HYPOTHALAMIC LESIONS

\begin{tabular}{l|c|c|c|c}
\hline & & Median No. mounts preoperative & \multicolumn{2}{c}{ Median No. mounts postoperative } \\
\cline { 2 - 5 } & $\mathcal{N}$ & Oestradiol and progesterone & $\begin{array}{c}\text { Oestradiol and } \\
\text { progesterone }\end{array}$ & Testosterone \\
\hline Group A & 4 & $24 \cdot 5$ & $2 \cdot 2$ & $2 \cdot 5$ \\
Group B & 7 & $12 \cdot 2$ & $0 \cdot 0$ & $3 \cdot 0^{*}$ \\
\hline
\end{tabular}

* Significant increase over postoperative mounting frequency with oestradiol and progesterone $(\mathrm{T}=0, P<0 \cdot 02)$.

With the exception of several cases of diabetes insipidus, the animals were in good health throughout the experiment. None of the animals showed any signs of hyperphagia or 'hypothalamic obesity'. When polydipsia and polyuria were observed, there was an accompanying loss in body weight. However, behavioural deficit was not confined to animals displaying these symptoms, nor did all the animals with these symptoms show losses of sexual behaviour. One animal showing complete loss of sexual behaviour had diabetes insipidus, but the other eight animals in this category were normal as judged by their drinking and eating behaviour, weight records, and general cage activity.

Supplementary evidence for lack of correlation between diabetes insipidus and loss of sexual behaviour was provided by five animals that developed severe cases during the postoperative series of tests. Their mean preoperative body weight dropped from $797 \mathrm{~g}$ to $622 \mathrm{~g}$. They were injected with 1.5 units of pitressin (Parke, Davis \& Co) every other day until they regained their preoperative weights. Their performance on tests at this time was no different from their earlier postoperative behaviour.

Two animals whose postoperative behaviour was judged to be normal showed severe diabetes insipidus. Although untreated with pitressin, their behaviour remained normal throughout the postoperative tests covering a 2-month period.

\section{ANATOMICAL RESULTS}

The hypothalamic lesions studied in the present series of animals varied considerably both in locus and size. None extended into areas rostral to the anterior border of the optic chiasm, and none extended beyond the caudal pole of the mammillary body. The region most frequently suffering complete destruction 


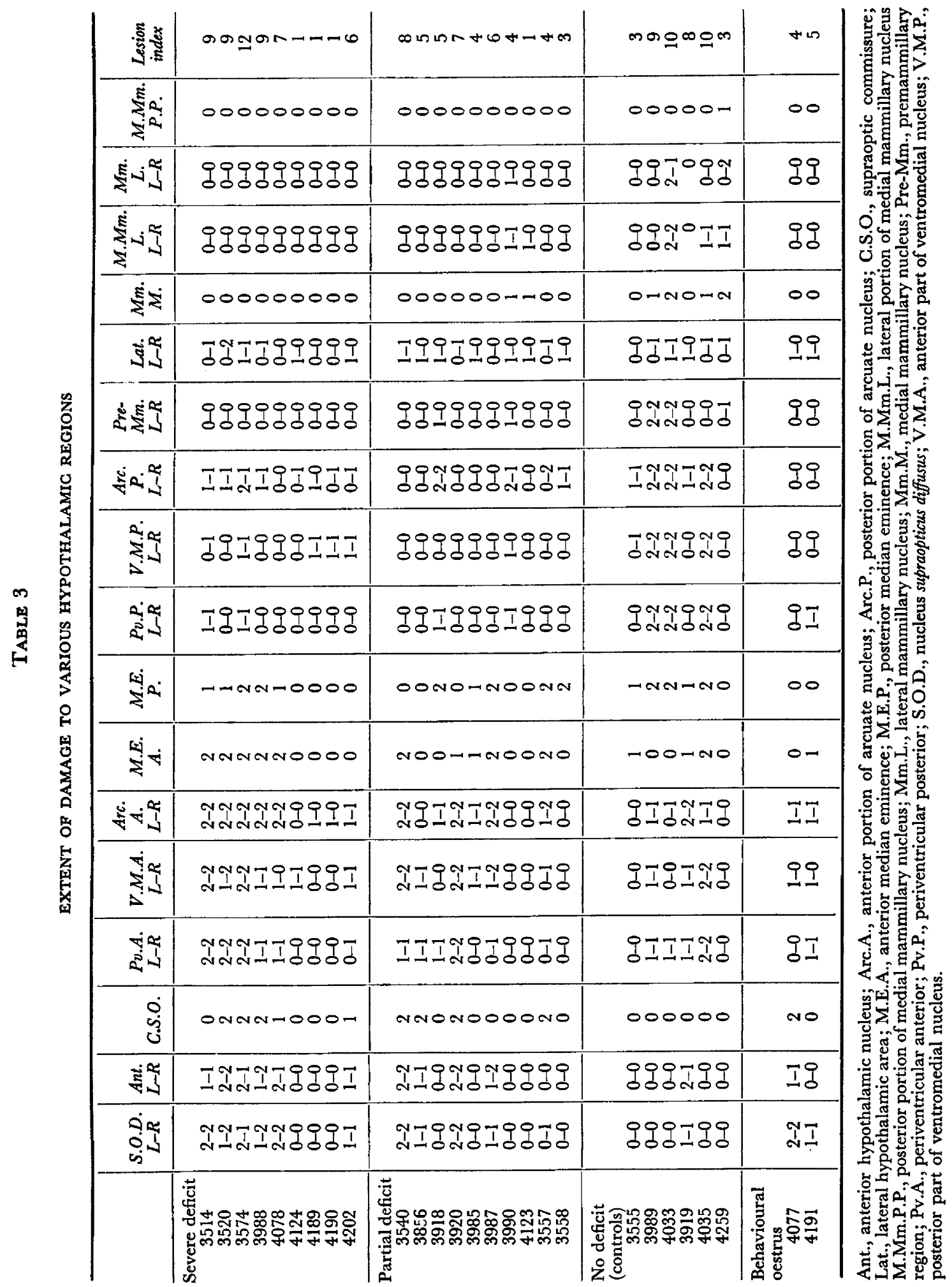


was the anterior median eminence (nine animals). The posterior part of the medial mammillary nucleus was not completely destroyed in any animal. The columns of the fornix generally delimited the lateral extent of damage, although invasion of the lateral areas frequently occurred especially on their more ventral aspects. Direct damage (except for that of the electrode tracks) never extended dorsally into the thalamus, but evidence of degenerated fibre tracts was found in subthalamic and thalamic areas.

The lesions never directly involved the supra-optic nuclei laterally, although a few cells distributed ventro-medially may have been directly involved. Similarly, no direct damage was imposed upon $\mathcal{N}$. filiformis magno-cellularis with the possible exception of the most ventrally and medially located cells.

Table 3 shows the ratings for damage to seventeen areas or nuclei within the hypothalamus for each animal. Damage to $\mathcal{N}$. suprachiasmaticus never exceeded $10 \%$ and was found in only three animals. Therefore we have not included ratings for this nucleus in Table 3.

An index to the extent of the hypothalamic damage for each animal was provided by counting the number of pairs of nuclei which suffered bilateral damage (regardless of the degree of damage). Assymetrical damage in particular nuclei was counted except when no damage (or less than $10 \%$ ) was observed on one side. Assymetry was regarded as a negligible factor for medial structures. The hypothalamic lesions varied from only one pair of nuclei or one medial structure damaged, to twelve structures damaged in the entire series of twentyseven animals. The lesion indices are reported in Table 3 . The median lesion index for the severe, partial, no deficit (controls) and behavioural oestrus groups were $6,5,8 \cdot 5$ and $4 \cdot 5$, respectively.

\section{BEHAVIOURAL - ANATOMICAL RESULTS}

Neither severe deficit nor partial deficit was consistently associated with the complete bilateral destruction of any one of the nuclear groups examined in the present study (Table 4). The supraopticus diffusus, anterior area, and supra-optic commissures were never completely destroyed bilaterally in any animal that showed 'normal' postoperative behaviour. At the same time, none of these structures was completely destroyed in more than one-third of the animals in the severe deficit group. The majority of animals in the severe deficit group (five out of nine) suffered complete destruction of the median eminence anterior and the anterior arcuate. Correspondingly, the majority (five out of eight) of the lesions which completely destroyed these structures were associated with severe behavioural deficits.

The postoperative deficits in behaviour were not associated with the extent of lesions as estimated by the lesion index. Tests of association between the lesion index and (a) the ability to display heat consistently, (b) latency to heat, (c) duration of maximum lordosis, and (d) the display of mounting, yielded chisquares always close to $1 \cdot 00$ and probabilities always greater than $0 \cdot 30$. Median values were used as the basis for classifying the animals' behaviour for each comparison. In addition, there was no significant difference in lesion index between those animals that mounted more following injection with testosterone propionate and those that failed to increase $(U=20, P>0 \cdot 10)$, and no specific 
nucleus was found to be crucial in determining the ability to respond to testosterone propionate by an increase in the display of mounting activity.

The brains of four females that showed severe deficits had relatively small lesions (4124, 4189, 4190 and 4202 in Table 3). The common area of destruction for these brains may be described as lying within the lateral extensions of the arcuate nucleus and ventrolateral portions of the ventromedial (Pl. 1, Figs. 1 to 4). For the most part, the lesions within the arcuate and ventromedial nuclei were too small to be given ratings of more than zero (less than $10 \%$ damage to the area as a whole). In control brains, the zones between the arcuate and adjacent nuclei (such as the ventromedial dorsolaterally and the

\section{TABLE 4}

DISTRIBUTION OF INDIVIDUALS FROM THREE POSTOPERATIVE BEHAVIOURAL CATEGORIES WITH RESPECT TO EXTENT OF DAMAGE AT DIFFERENT HYPOTHALAMIC LOCI

\begin{tabular}{|c|c|c|c|c|c|c|c|c|c|}
\hline \multirow{2}{*}{$\begin{array}{l}\text { Nucleus } \\
\text { or area }\end{array}$} & \multicolumn{3}{|c|}{ Severe deficit $(\mathcal{N}=9)$} & \multicolumn{3}{|c|}{ Partial deficit $(\mathcal{N}=10)$} & \multicolumn{3}{|c|}{ Controls $(\mathcal{N}=6)$} \\
\hline & \multicolumn{3}{|c|}{$\begin{array}{ll}\text { Degree damage } \\
0\end{array}$} & \multicolumn{3}{|c|}{$\begin{array}{ll}\text { Degree damage } \\
0 & 1\end{array}$} & & Degree damage & $\begin{array}{c}\text { age } \\
2\end{array}$ \\
\hline S.O.D. & 3 & 4 & 2 & 6 & 2 & 2 & 5 & 1 & 0 \\
\hline Ant. & 3 & 5 & $\overline{1}$ & 6 & 2 & 2 & 5 & 1 & 0 \\
\hline G.S.O. & 4 & 2 & 3 & 6 & 0 & 4 & 6 & 0 & 0 \\
\hline Pv.A. & 4 & 2 & 3 & 6 & 3 & 1 & 2 & 4 & 0 \\
\hline V.M.A. & 3 & 4 & 2 & 5 & 3 & 2 & 3 & 2 & 1 \\
\hline Arc. A. & 3 & 1 & 5 & 4 & 3 & 3 & 3 & 2 & 1 \\
\hline M.E.A. & 4 & 0 & 5 & 5 & 2 & 3 & 3 & 2 & 1 \\
\hline M.E.P. & 4 & 3 & 2 & 5 & 1 & 4 & 1 & 2 & 3 \\
\hline Pv.P. & 7 & 2 & 0 & 8 & 2 & 0 & 3 & 0 & 3 \\
\hline V.M.P. & 5 & 4 & 0 & 10 & 0 & 0 & 3 & 0 & 3 \\
\hline Arc.P. & 5 & 4 & 0 & 7 & 2 & 1 & 1 & 2 & 3 \\
\hline Pre-Mm. & 9 & 0 & 0 & 10 & 0 & 0 & 4 & 0 & 2 \\
\hline Lat. & 8 & 1 & 0 & 9 & 1 & 0 & 5 & 1 & $\overline{0}$ \\
\hline Mm.M. & 9 & 0 & 0 & 8 & 2 & 0 & 3 & 1 & 2 \\
\hline M. Mm.L. & 9 & 0 & 0 & 9 & $i$ & 0 & 2 & 3 & 1 \\
\hline Mm.L. & 9 & 0 & 0 & 10 & 0 & 0 & 5 & 1 & 0 \\
\hline M.Mm.P.P. & 9 & 0 & 0 & 10 & 0 & 0 & 5 & 1 & 0 \\
\hline
\end{tabular}

Numbers in the table refer to number of individuals. In cases where destruction to paired nuclei was not bilaterally uniform, the damage rating for the side with lesser damage was used. Abbreviations as in Table 3.

medial extension of the mammillary prelateralis) are represented by regions quite deficient in nerve cell bodies. The lesions in the four brains from the severe deficit group were localized predominantly in these cell-poor zones, close to or on the ventral surface of the hypothalamus. In the cephalo-caudal axis, the lesions all appeared at the level of the infundibular protuberance but anterior to the posterior median eminence. In all four brains bilateral lesions appeared in the sixth section $(15 \mu \times 10 \times 6)$ caudal to the first appearance of the cells of pars tuberalis on the ventral surface of the brain.

Lesions in animals from the control (no behavioural deficit) and the behavioural oestrous groups, never appeared bilaterally in the region which was common to animals from the severe deficit group. When both the no deficit and behavioural oestrous groups were combined (as a control for lesions not 
associated with loss of behaviour) and compared to the four severe deficit females for incidence of bilateral damage in the lateral extensions of arcuate, the ventrolateral portions of the ventromedial, and adjacent regions, the groups differed significantly $(P<0.005)$.

We were unable to evaluate this region in a comparable fashion for the remaining animals in the severe deficit group because of the extensive nature of their lesions. In most, destruction of the median eminence anterior was complete, the infundibular stalk was involved, and the cells of pars tuberalis (used as a landmark in the other brains) were extensively destroyed on the ventral surface of the brain. The extensiveness of the damage in this general area, however, strongly suggests that the critical region in the lateral extension of the arcuate was destroyed in all females showing severe behavioural deficits.

The lesions for the two females displaying behavioural oestrus without injection of oestradiol and progesterone differed considerably from each other in size. The section showing maximum destruction in the brain of Female 4077 is illustrated in Pl. 1, Fig. 5. The region destroyed is within the nucleus supraopticus diffusus and is more anterior than lesions which eliminated sexual behaviour. The possibility of a locus confined to midline structures cannot be excluded.

\section{DISCUSSION}

In previous studies (Sawyer \& Robinson, 1956; Law \& Meagher, 1958; Brookhart, Dey \& Ranson, 1940), the investigators have confined their attention largely or exclusively to animals in which the behavioural decrements were complete. In our experiments, the application of quantitative methods to the evaluation of behaviour changes has demonstrated a range of partial decrements. We do not consider that these partial decrements are due to any general or profound physiological disturbance, for, with the exception of several cases of polydipsia, the general behaviour of the animals was normal. Females that failed to come into heat showed normal and vigorous evasive reactions when attempts were made to elicit lordosis. Moreover, animals with decrements showed no tendency to improve with time, and their sexual behaviour was diminished or absent even when tested 2 to 3 months postoperatively. In an earlier study on the male guinea-pig (Phoenix, 1961), comparable partial decrements in sexual performance after hypothalamic lesions were reported. Apparently a more quantitative relationship exists between hypothalamus and sexual behaviour than the 'all-or-nothing' effects reported in earlier studies. In a number of ways this relationship appears similar to that between the hypothalamus and eating behaviour (Brobeck, 1960; Patton, 1961).

Attempts to account for incomplete quantitative decrements in either the pattern of oestrus as a whole or in any of the individual components have not provided a satisfactory hypothesis. According to Beach $(1940,1943)$, the effect of cortical destruction on the mounting activity of male and female rats is proportional to the size of the lesion. A similar relationship does not exist between our hypothalamic lesions and sexual activity in the female guinea-pig. The evidence obtained in our study cannot support a concept of equipotentiality of hypothalamic tissues in the regulation of sexual behaviour. Only in so far as increasing the size of the lesion increases the probability of destroying relevant 
structures can such a correlation between amount of destruction and degree of behavioural loss be said to exist. If the factor of lesion size does not account for the range of quantitative decrements obtained in our study, we are unable to offer any alternative. More refined lesions than those we have utilized may account for partial behavioural decrements in terms of incomplete destruction of the relevant structures.

Ordinarily testosterone propionate greatly facilitates mounting behaviour (Ball, 1940; Phoenix, Goy, Gerall \& Young, 1959). In the present study, neither oestradiol nor testosterone materially altered the frequency of mounting displayed by many postoperative females. The loss of mounting observed after hypothalamic injury may reflect either a loss in the responsiveness of the neural elements to stimulation by gonadal hormones, or a loss of the responding neural elements themselves. Without additional experiments we are unable to decide between these alternatives.

A hypothalamic mechanism essential to the display of sexual behaviour has been demonstrated for all mammalian females studied. But when the results of this study are compared to previous findings, species differences appear to exist with respect to the locus of hypothalamic lesions which eliminate the behaviour. The smallest effective lesions in the female guinea-pig according to our results are at the level of the anterior infundibular protuberance in the lateral extensions of the arcuate nucleus and adjacent ventral regions. Law \& Meagher (1958) state that the effective lesion in the female rat is located at the posterior border of the optic chiasma. Destruction of the anterior hypothalamic region is believed effective in eliminating sexual behaviour in the ewe (Clegg et al., 1958). In the female cat, effective lesions do not appear to be confined to morphologically defined nuclear groups, and Sawyer \& Robison (1956) have designated the locus simply as the lateral area of the anterior hypothalamic region. The same authors describe the effective site in the female rabbit as the mammillary region. No significance can be attached to species differences in hypothalamic loci since the different loci bear no obvious relationship to differences in the physiology of reproductive behaviour among lagomorphs, rodents, ungulates and carnivores.

Several writers (Beach, 1952, 1958; Young, 1953; Aronson, 1959) have emphasized the prominent differences between species with respect to the degree to which sexual behaviour depends upon the gonadal hormones. In general, the female sexual behaviour of lower mammals demonstrates the most rigid dependence on the gonadal hormones, that of infrahuman primates less, and that of man least. It is not suggested here that these taxonomic differences in degree of dependence on ovarian hormones can be accounted for by changes in neural organization solely within the hypothalamus. Nevertheless, our results and those of Law \& Meagher (1958) suggest that alterations in hypothalamic organization may be an important factor. In both studies, experimental alterations of hypothalamic organization permitted females from lower mammalian species to display sexual behaviour in the absence of ovarian hormones. Moreover, independence of sexual behaviour from hormonal factors can be effected by electrical stimulation of the hypothalamus in the female rat (P. Karinen and T. Law, personal communication). 
Among laboratory rodents, the display of lordosis has long been considered to depend entirely on the presence of adequate oestrogen-progesterone stimulation, and to our knowledge no case of the spontaneous and persistent display of the behaviour by spayed females lacking ovarian remnants has ever been reported. The display of oestrous behaviour has been observed in spayed rabbits lacking ovarian remnants. The behavioural responses are, however, inconstant, unreliable, and lacking the vigor characteristic of hormonally induced reactions. In short, the oestrous reactions of the spayed rabbit are not comparable to those displayed by our two females with behavioural oestrus following hypothalamic damage.

In this presentation, we have advanced the interpretation that behavioural oestrus can be established in spayed female guinea-pigs by hypothalamic lesions alone without the participation of oestrogen and/or progesterone. The validity of this interpretation relies heavily upon the conclusion that oestrogen is not being provided from any source. The assumption that tissues of the genital tract (such as the uterus and the vaginal membrane) will detect any quantity of oestrogen adequate for behavioural oestrus is not beyond criticism. Consideration may be given to the possibilities that (1) the behavioural responses have a lower threshold for activation than changes in the genital tract, (2) some oestrogen with effects relatively specific to behavioural end-points is present, and (3) some factor is being supplied which selectively inhibits the response of the genital tract tissues. This third possibility is immediately ruled out by the observation that when oestradiol and progesterone were injected postoperatively into the two females displaying behavioural oestrus, their vaginal membranes did respond by spontaneous rupture at the expected time. Of the remaining two possibilities which have occurred to us, only the first seems to merit additional comment. We are aware that behavioural oestrus can be induced by quantities of injected hormone which are too small to induce full vaginal oestrus. Never in our prior experience, however, has a female guinea-pig been brought to full behavioural expression for a protracted period without at least partial responses being detected in the distal genital tract. What kind of hormone and what manner of secretion would be required for such discrete effects cannot now be envisioned. We accept as parsimonious the conclusion that those hypothalamic lesions in the two behaviourally oestrous females involve an area which normally functions to inhibit the display of sexual behaviour.

Destruction of the amygdala and adjacent pyriform cortex has been associated with a 'release from sexual inhibition' (Klüver \& Bucy, 1939; Schreiner \& Kling, 1953, 1954, 1956; Green, Clemente \& de Groot, 1957). Because of the numerous relations between pyriform-amygdaloid regions and anterior hypothalamic structures, interruption of relational pathways might be considered a possible basis for the behavioural oestrus observed by us in female guinea-pigs and by Law \& Meagher (1958) in female rats. But certain important differences in the character of the postoperative behaviour make the destruction of anatomical pathways between these regions an unlikely cause. Sexual responses after hypothalamic damage are not intensified or otherwise made abnormal as they appear to be after pyriform-amygdaloid damage. Pyriform-amygdaloid lesions have so far been shown to alter only the reproductive pattern in the male and 
their effects on behaviour are not independent of the gonadal hormones. This latter factor alone clearly distinguishes the hypothalamic 'release' from that observed following pyriform-amygdaloid destruction.

Recently the techniques of electrophysiology (Porter, Cavanaugh, Critchlow \& Sawyer, 1957; Sawyer \& Everett, 1959; Sawyer \& Kawakami, 1959; Kawakami \& Sawyer, 1959 a, b), self stimulation (Olds, 1958) and autoradiography (Michael, 1962) have provided convincing evidence for the selective sensitivity of hypothalamic neuronal elements to the gonadal hormones. The effects of hypothalamic lesions in the female rat and guinea-pig suggest relationships between the gonadal hormones and the neurological substrate that have not been generally recognized. The possibility that the oestrogen-progesterone synergism common among laboratory rodents may suppress activity in a region which normally inhibits sexual activity deserves further attention.

\section{ACKNOWLEDGMENTS}

We are indebted to the Schering Corporation, Bloomfield, New Jersey, for supplies of oestradiol benzoate (Progynon Benzoate) and to Ciba Pharmaceutical Products, Inc, Summit, New Jersey for testosterone propionate (Perandren). The investigation was supported by Research Grant M-504 to W. C. Young from the United States Public Health Service, National Institute of Mental Health. We acknowledge our appreciation of the help provided in the preparation of the manuscript by the University of Wisconsin Regional Primate Center.

\section{REFERENCES}

Anand, B. K. \& Brobeck, J. R. (1951) Hypothalamic control of food intake in rats and cats. rale $\mathcal{F}$. Biol. Med. 24, 123.

Aronson, L. R. (1959) Hormones and reproductive behaviour: some phylogenetic considerations. Comparative Endocrinology. Ed. A. Gorbman. Wiley, New York.

Ball, J. (1940) The effect of testosterone on the sex behaviour of female rats. F. comp. Psychol. 29, 151.

BEACH, F. A. (1940) Effects of cortical lesions upon the copulatory behaviour of male rats. $\mathcal{7}$. comp. Psychol. 29, 193.

BEACH, F. A. (1943) Effects of injury to the cerebral cortex upon the display of masculine and feminine mating behavior by female rats. F. comp. Psychol. 26, 169.

BEACH, F. A. (1952) Sex and species differences in the behavioural effects of gonadal hormones. Ciba Foundation Colloquia in Endocrinology, 3, 3.

BEACH, F. A. (1958) Evolutionary aspects of psychoendocrinology. Behaviour and Evolution. Ed. Anne Roe and G. G. Simpson. Yale University Press.

BRoBeck, J. R. (1960) Regulation of feeding and drinking. Handbook of Physiology; Sect. 1, Neurophysiology, Vol. II. Ed. J. Field, H. W. Magoun and V. E. Hall. Waverly Press, Baltimore.

BRookhart, J. M. \& Dey, F. L. (1941) Reduction of sexual behaviour in male guinea-pigs by hypothalamic lesions. Amer. F. Physiol. 133, 551.

Brookhart, J. M., Dey, F. J. \& Ranson, S. W. (1940) Failure of ovarian hormones to cause mating reactions in spayed guinea pigs with hypothalamic lesions. Proc. Soc. exp. Biol., N.Y. 44, 61 .

Glark, G. (1942) Sexual behaviour in rats with lesions in the anterior hypothalamus. Amer. F. Physiol. $137,746$.

Clegg, M. T., Santolucito, J. A., Smith, J. D. \& Ganong, W. F. (1958) The effect of hypothalamic lesions on sexual behaviour and estrous cycles in the ewe. Endocrinology, 62, 790.

DEY, F. L. (1943a) Evidence of hypothalamic control of hypophyseal gonadotropic functions in the female guinea pig. Endocrinology, 33, 74.

Dey, F. L. (1943b) Genital changes in female guinea pigs resulting from destruction of the median eminence. Anat. Rec. 87, 85.

Goy, R. W. \& Phoenix, C. H. (1960) Hypothalamic lesions and sexual behavior in the female guinea pig. Anat. Rec. 136, 314.

Goy, R. W. \& Young, W. G. (1957) Strain differences in the behavioural responses of female guinea pigs to alpha-estradiol benzoate and progesterone. Behaviour, 10, 340 . 
Green, J. D., Clemente, C. D. \& de Groot, J. (1947) Rhinencephalic lesions and behaviour in cats. F. comp. Neurol. 108, 505.

GurdjuAN, E. S. (1927) The diencephalon of the albino rat. F. comp. Neurol. 43, 1.

Hetherington, A. W. \& Ranson, S. W. (1940) Hypothalamic lesions and adiposity in rat. Anat. Rec. 78, 149.

KAWAKAMI, M. \& SAWYER, C. H. (1959a) Induction of behavioral and electroencephalographic changes in the rabbit by hormone administration or brain stimulation. Endocrinology, 65, 631.

KaWAKam, M. \& SAWXeR, C. H. (1959b) Neuroendocrine correlates of changes in brain activity thresholds by sex steroids and pituitary hormones. Endocrinology, 65, 652 .

KLüver, H. \& BARRERA, E. (1953) A method for the combined staining of cells and fibers in the nervous system. F. Neuropath. exp. Neurol. 12, 400.

KLüver, H. \& BuCY, P. C. (1939) Preliminary analysis of the functions of the temporal lobes in monkeys. Arch. Neurol. Psychiat. 42, 979.

KRIEG, W. J. S. (1932) The hypothalamus of the albino rat. F. comp. Neurol. 55, 19.

LAw, T. \& MEAGHeR, W. (1958) Hypothalamic lesions and sexual behavior in the female rat. Science, $128,1626$.

Michael, R. P. (1962) Estrogen-sensitive neurons and sexual behavior in female cats. Science, 136, 322.

Nakao, H. (1958) Emotional behaviors produced by hypothalamic stimulation. Amer. F. Physiol. 194, 411.

OLDs, J. (1958) Selective effects of drives and drugs on 'reward' systems of the brain. Neurological Basis of Behaviour, Ciba Foundation Symposium. Little-Brown, Boston.

Patron, H. D. (1961) Higher control of autonomic outflows; the hypothalamus. Neurophysiology. Ed. T. C. Ruch and J. F. Fulton. Saunders, Philadelphia.

Phoendx, G. H., Gox, R. W., Gerall, A. A. \& Young, W. G. (1959) Organizing action of prenatally administered testosterone propionate on the tissues mediating mating behavior in the female guinea pig. Endocrinology, 65, 369.

Phoznix, C. H. (1961) Hypothalamic regulation of sexual behavior in male guinea pigs. $\mathcal{F}$. comp . Physiol. Psychol. 54, 72.

Porter, R. W., Cavanaugh, E. B., Gritchlow, B. V. \& Sawyer, C. H. (1957) Localized changes in electrical activity of the hypothalamus in estrous cats following vaginal stimulation. Amer. $\mathcal{J}$. Physiol. 189, 145.

RIoch, D. M., Wislocki, G. B. \& O'Leary, J. L. (1940) A precis of preoptic, hypothalamic and hypophysial terminology with atlas. Res. Publ. Ass. nerv. ment. Dis. 20, 3.

Ruch, T. C. (1961) Neurophysiology of emotion and motivation. Neurophysiology. Ed. T. C. Ruch and J. F. Fulton. Saunders, Philadelphia.

SAwyer, C. H. (1959) Nervous control of ovulation. Recent Progress in the Endocrinology of Reproduction. Ed. C. W. Lloyd. Academic Press, New York.

SAwyer, C. H. (1960) Reproductive behavior. Handbook of Physiology; Section 1, Neurophysiology, Vol. II. Ed. J. Field, H. W. Magoun and V. E. Hall. Waverly Press, Baltimore.

SAWyer, C. H. \& Everett, J. W. (1959) Stimulatory and inhibitory effects of progesterone on the release of pituitary ovulating hormone in the rabbit. Endocrinology, 65, 644.

SAWYER, G. H. \& KAWAKAMI, M. (1959) Characteristics of behavioral and electroencephalographic after-reactions to copulation and vaginal stimulation in the female rabbit. Endocrinology, 65, 622.

SAWYER, C. H. \& RoBison, B. L. (1956) Separate hypothalamic areas controlling pituitary gonadotropic functions and mating behavior in female cats and rabbits. F. clin. Endocrin. Metab. 16, 914.

SCHREINER, L. \& Kirng, A. (1953) Behavioral changes following rhinencephalic injury in cat. $\mathcal{F}$. Neurophysiol. 16, 643.

SchreINer, L. \& KLING, A. (1954) Effects of castration on hypersexual behavior induced by rhinencephalic injury in cat. Arch. Neurol. Psychiat. 72, 180.

Schreiner, L. \& King, A. (1956) Rhinencephalon and behavior. Amer. F. Physiol. 184, 486.

Soulairac, A. (1959) Les lesions gonadiques et les troubles du comportement sexuel. Probl. Endocrin. Nutrit. 3, 1.

Soulairac, A., Soulairac, M. L. \& Giabicani-Teysseyre, J. (1958) Modification du comportement sexuel du rat male apres lesions hypothalamiques. Pathophysiologia Diencephalica. Ed. W. Kovac, S. B. Curviet et L. Martini. Springer, Wien. 
Sterlar, E. (1960) Drive and motivation. Handbook of Physiology; Section 1, Neurophysiology, Vol. III. Ed. J. Field, H. W. Magoun and V. E. Hall. Waverly Press, Baltimore.

Young, W. G. (1953) Gamete age at the time of fertilization and the course of gestation in mammals. Pregnancy and Wastage. Ed. E. T. Engle. Thomas, Springfield.

WheAtLEY, M. D. (1944) Hypothalamus and affective behavior in cats: study of effects of experimental lesions, with anatomic correlations. Arch. Neurol. Psychiat. 52, 296. 


\section{EXPLANATION OF PLATE 1}

Fig. 1. Section from 'severe deficit' Female 4189 through the anterior infundibular protuberance $1 \mathrm{~mm}$ caudal to the first appearance of the cells of pars tuberalis of the pituitary: on the left side of the brain the electrode track passes through the medial edge of the fornix and ends ventrally in the area of marked gliosis. On the right, only the electrode track is visible because of the asymmetry of sectioning $(\times 20)$.

Fig. 2. Section from 'severe deficit' Female 4124 at the same level as above: the left fornix is completely destroyed and the right is partially damaged. The lesions show good bilateral symmetry $(\times 20)$.

FIg. 3. Section from 'severe deficit' Female 1490 at the same level as above: the left fornix is again completely destroyed. Only the medial aspects of the lesions display symmetry and the left lesion extends farther laterally than the right $(\times 20)$.

FIG. 4. Section from 'severe deficit' Female 4202: this brain had the largest lesion of the four complete-loss females illustrated in the plate. Damage to the ependyma of the third ventricle resulted from insertion of a midline electrode not utilized in producing the lesions in the other three animals $(\times 20)$.

Fig. 5. Section from 'behavioural oestrus' Female 4077 at the level of maximum extent of lesion: the level is considerably more rostral than the level illustrated for the four 'severe deficit' females. The extensive nature of the lesion is clear from its infringement on the optic tracts laterally and its complete destruction of midline structures $(\times 20)$.

Figs. 6 and 7. High- and low-power photomicrographs of uterus from Female 4077: the luminal epthelium is low and cuboidal, the myometrium is thin, and the glandular epithelium is inactive. By direct measurement, the narrow diameter of the uterus is $1.1 \mathrm{~mm}$. (Magnifications, $\times 85$ and $\times 35$, respectively). 
PLATE I

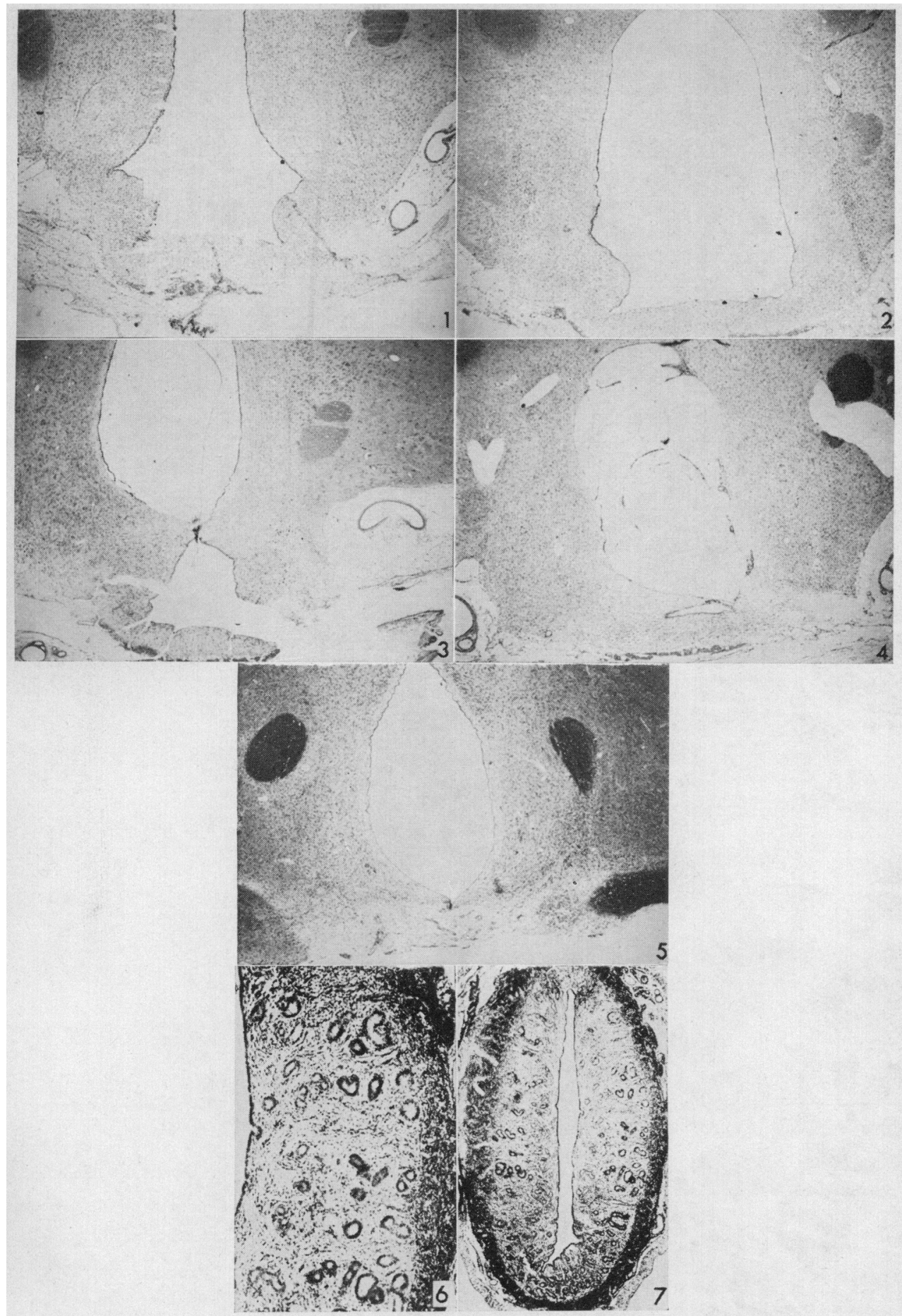

(Facing p. 40) 